\title{
Prevention and Management of Hormonal Crisis during Theragnosis with LU-DOTA-TATE in Neuroendocrine Tumors. A Systematic Review and Approach Proposal
}

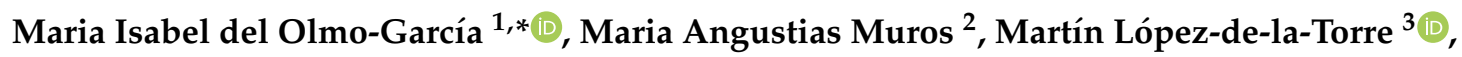 \\ Marc Agudelo ${ }^{4}$, Pilar Bello ${ }^{4}$, Jose M. Soriano ${ }^{5,6}(\mathbb{D}$ and Juan-Francisco Merino-Torres 1,6 (D) \\ 1 Endocrinology and Nutrition Department, University and Polytechnic Hospital La Fe, 46026 Valencia, Spain; \\ merino_jfr@gva.es \\ 2 Nuclear Medicine Department, University Hospital Virgen de las Nieves, 18014 Granada, Spain; \\ mangustias.muros.11pa@juntadeandalucia.es \\ 3 Endocrinology and Nutrition Department, University Hospital Virgen de las Nieves, 18014 Granada, Spain; \\ m.endocrino@gmail.com \\ 4 Nuclear Medicine Department, University and Polytechnic Hospital La Fe, 46026 Valencia, Spain; \\ marc-agudelo@hotmail.com (M.A.); bello_pil@gva.es (P.B.) \\ 5 Food \& Health Lab, Institute of Materials Science, University of Valencia, 46980 Valencia, Spain; \\ jose.soriano@uv.es \\ 6 Joint Research Unit on Endocrinology, Nutrition and Clinical Dietetics, University of Valencia-Health \\ Research Institute La Fe, 46026 Valencia, Spain \\ * Correspondence: maribeldelolmo@gmail.com
}

Received: 11 June 2020; Accepted: 7 July 2020; Published: 12 July 2020

\begin{abstract}
Neuroendocrine tumors (NETs) frequently overexpress somatostatin receptors (SSTR) on their cell surface. The first-line pharmacological treatment for inoperable metastatic functioning well-differentiated NETs are somatostatin analogs. On second line, Lu-DOTA-TATE ( ${ }^{177}$ Lu-DOTA ${ }^{0}$ $\mathrm{Tyr}^{3}$ octreotate) has shown stabilization of the disease and an increase in progression free survival, as well as effectiveness in controlling symptoms and increasing quality of life. The management of functional NETs before and during LU-DOTA-TATE treatment is specially challenging, as several complications such as severe carcinoid and catecholamine crisis have been described. The aim of this review is to establish practical guidance for the management and prevention of the most common hormonal crises during radionuclide treatment with Lu-DOTA-TATE: carcinoid syndrome (CS) and catecholamine hypersecretion, as well as to provide a brief commentary on other infrequent metabolic complications. To establish a practical approach, a systematic review was performed. This systematic review was developed according to the Preferred Reporting Items for Systematic Reviews and Meta-Analyses (PRISMA) statement and conducted using MEDLINE (accessed from PubMed), Google Scholar and ClinicalTrials.gov. Literature searches found 449 citations, and finally nine were considered for this systematic review.
\end{abstract}

Keywords: neuroendocrine tumors; peptide receptor radionuclide therapy; 177Lu-DOTA-TATE; hormonal crisis; carcinoid syndrome; carcinoid crisis; catecholaminergic crisis; systematic review

\section{Introduction}

Neuroendocrine neoplasms (NENs) have been usually described as infrequent and rare tumors but their incidence has been rising over time [1]. Neuroendocrine cells are distributed widely throughout the body and these tumors may arise in most organs. NENs are classified according to the rate of 
proliferation (mitotic rate and Ki-67 proliferative index) and differentiation. Accordingly, the World Health Organization (WHO) has classified NENs as neuroendocrine tumors (NETs) subclassified as G1, G2 and G3 according to mitotic rate, proliferative index and poorly differentiated (neuroendocrine carcinomas NECs). This classification has been approved for gastrointestinal and pancreatic NENs. However, NENs arising in bronchial or other localizations do not follow this same classification [2].

Morphologically, well-differentiated NETs have characteristic organoid arrangements with glandular, trabecular or solid nest arrangements. These cells produce abundant neurosecretory granules as reflected in the strong and diffuse immunohistochemical expression of neuroendocrine markers. In addition, some tumors may secrete specific peptide hormones or bioamines which may produce clinically evident hormonal syndromes (functioning NETs) and their localization may vary (pancreas, midgut, foregut, bronchial) [3].

Paragangliomas and pheochromocytomas (PPGL) are another kind of rare neuroendocrine tumor with a reported annual incidence of 1 in 300.000. [4] PPGLs arise from the extra-adrenal autonomic paraganglia (paraganglioma) or adrenal medulla (pheochromocytoma). Paraganglia are small organs consisting mainly of neuroendocrine cells derived from the embryonic neural crest and may have the ability to secrete catecholamines (usually those on an infra-diafragmatic location) and therefore of producing hormonal syndromes as well as those which arise from the adrenal medulla (pheochromocytoma) [4].NETs are heterogeneous malignancies; however, many of them have in common their ability to overexpress somatostatin receptors (SSTR) on their cell surface. Five receptor subtypes for SSTR have been identified: SSTR1, SSTR2, SSTR3, SSTR4 and SSTR5. GEP-NENs (gastroenteropancreatic neuroendocrine neoplasms) especially overexpress SSTR2 compared to healthy tissue, which is the cornerstone of the concept of theragnosis in these tumors. The expression of SSTR may vary within the different NETs (Table 1) [5,6].

Table 1. SSTR expression in NETs according to WHO classification and primary site. +++ , SSTR expression 80-100\%; + +, SSTR expression 30-80\%; +, SSTR expression 15-30\%; - , SSTR expression < 15\%.

\begin{tabular}{cccccc}
\hline WHO Classification & SSTR1 & SSTR2 & SSTR3 & SSTR4 & SSTR5 \\
\hline G1 & +++ & +++ & ++ & - & +++ \\
G2 & +++ & +++ & ++ & - & ++ \\
G3 & +++ & +++ & ++ & - & - \\
Primary Site & SSTR1 & SSTR2 & SSTR3 & SSTR4 & SSTR5 \\
Pancreas & - & +++ & - & - & ++ \\
Insulinoma & + & ++ & ++ & - & ++ \\
Gastrinoma & + & +++ & ++ & - & ++ \\
Gastric & - & +++ & - & - & ++ \\
Intestinal & - & ++ & - & - & ++ \\
Pulmonary & & & & & - \\
Typical carcinoma & ++ & +++ & ++ & - & - \\
Atypical carcinoma & ++ & ++ & + & - & + \\
Large cell & ++ & ++ & ++ & - & - \\
Small cell & + & ++ & + & - & ++ \\
Pheochromocytoma & +++ & +++ & ++ & - & ++ \\
Paraganglioma & +++ & +++ & ++ & - & + \\
\hline
\end{tabular}

Somatostatin receptors (SSTR); neuroendocrine tumors (NETs); World Health Organization (WHO).

Among the nuclear medicine imaging techniques, some are based on SSTR expression, such as somatostatin receptor scintigraphy (SRS). Within the conventional radiopharmaceuticals used in SRS, 111In-labeled somatostatin analogs were initially developed: the best known is the 111In-labeled octreotide and diethylene triamine penta-acetic (DTPA), called 111In-DTPA -Pentreotide (111InOctreoscan ${ }^{\circledR}$, Tyco Healthcare, Mallinckrodt, St Louis, MO, USA). For several years this has been considered the gold standard of functional imaging [6]. Subsequently, 99mTc-labeled radiopharmaceuticals which aim to use gamma-emitting isotopes, which are easier to handle and more 
available, were developed $\left((99 \mathrm{mTc})\right.$ such as EDDA-HYNIC-Thr3-octreotide $\left((99 \mathrm{mTc})\right.$ TEKTROTYD ${ }^{\circledR}$, Polatom, Otwock, Poland) [7,8].

Positron emission tomography (PET) uses positron-emitting radioisotopes (18F, 11C, 68Ga), a new generation of tracers whose shorter half-life reduces patients' radiation. In addition, PET offers a higher spatial resolution, detects more lesions, and allows a quantification of their uptake (standard uptake value, SUV) of great utility in therapy monitoring [9]. These are the studies currently considered of whenever they are available, since they change the follow-up strategy in more than $70 \%$ of patients [10].

Current recommendations suggest that the conventional 111In-pentetreotide single-photon emission computed tomography (SPECT/CT) scan should be replaced by the 68 Ga-DOTA-SSA PET/CT. 68 Ga-DOTA-SSA PET/CT has a greater sensitivity, shorter duration of image acquisition, better spatial resolution, diagnostic accuracy, lower radiation dose for the patient and [11] is more readily available in nuclear medicine departments (it is a generator product instead of a cyclotron). Its ability to penetrate tissues is higher, so that the radiation dose of 68 Ga-peptide is $<50 \%$ of the 111In-pentetreotide dose, and in addition 68 Ga-peptide has a higher affinity for the somatostatin receptor [12]. Basic research usually defines the specific molecular target of a specific disease (i.e., receptor, metabolite). Theragnosis involves changing the use of the radioisotope to offer the possibility of using molecular imaging beyond diagnostic purposes and developing targeted radionuclide therapy: One of the most widely used theragnostic agents targeting NETs is metaiodobenzylguanidine (MIBG), a guanethidine analogue of norepinephrine. 123I/131I-MIBG theragnostics have been applied in the clinical evaluation and management of NETs, especially in neuroblastoma, paraganglioma, and pheochromocytoma. 177Lu-DOTATE is also a theragnostic agent used in the field of NET treatment [13]. The first-line pharmacological treatment for inoperable metastatic functioning well-differentiated NETs are somatostatin analogs (SSA). SSA have proven antiproliferative effects in non-functional NETs as well as causing a substantial decrease in hormonal secretion and remission of hormonal hypersecretory syndromes. When disease progresses in this first line treatment other available medical treatments include everolimus, sunitinib, and cytotoxic chemotherapy. A promising targeted therapy is Peptide Receptor Radionuclide therapy (PRRT) with (Lutetium-177-DOTA0-Tyr3) octreotate, which in a significant number of clinical studies has shown stabilization of the disease and an increased progression free survival (PFS), effectiveness in controlling symptoms and an increase in quality of life. In a recent trial, NETTER 1, Lu-DOTA-TATE controlled tumor growth in patients with inoperable, progressive, metastatic, non-functional small intestine NETs. Other large institutional series that include pancreatic NET have revealed high rates of tumor control after PRRT [3,14].

$177 \mathrm{Lu}-D O T A-T A T E$ has also been described as useful in NETs in other localizations. A cohort study conducted in patients with gastro-entero-pancreatic NETs (GEP NETs), NETs of unknown origin and bronchial tumors revealed that 177Lu-DOTA-TATE treatment determined a progression-free survival of 29 months and an overall survival of 63 months. The response rate of 177Lu-DOTA-TATE treatment was $39 \%$, reaching stabilization of the disease in $43 \%$ of patients [15]. The use of PRRT in PPGL has been explored in two small cohorts of patients with inoperable mediastinal or head and neck PPGL, with promising outcomes in terms of tumor response and symptomatic control. The other study was performed in a higher number of patients $(n=20)$. They received four cycles of Lu-DOTATATE with encouraging results in terms of symptomatic control (decreased medication requirements), biochemical control (circulating chromogranin A), tumor response and general control of the disease with a median PFS of 29 months. An ongoing prospective clinical trial at the National Institute of Health (NIH) evaluating PRRT for progressive PPGL will provide definite answers regarding the utility and safety of PRRT in PPGL [16].

The management of functional NETs before and during LU-DOTA-TATE treatment is specially challenging. Several complications such as severe carcinoid and catecholamine crisis have been described (Figures 1 and 2). The exact mechanism by which these hormonal crises take place during treatment has yet to be elucidated, as there are few reported cases in the literature. Several mechanisms 
have been postulated, such as SSA discontinuation, emotional stress, amino acid administration during infusion or tumoral lysis due to beta irradiation from 177Lu [17].

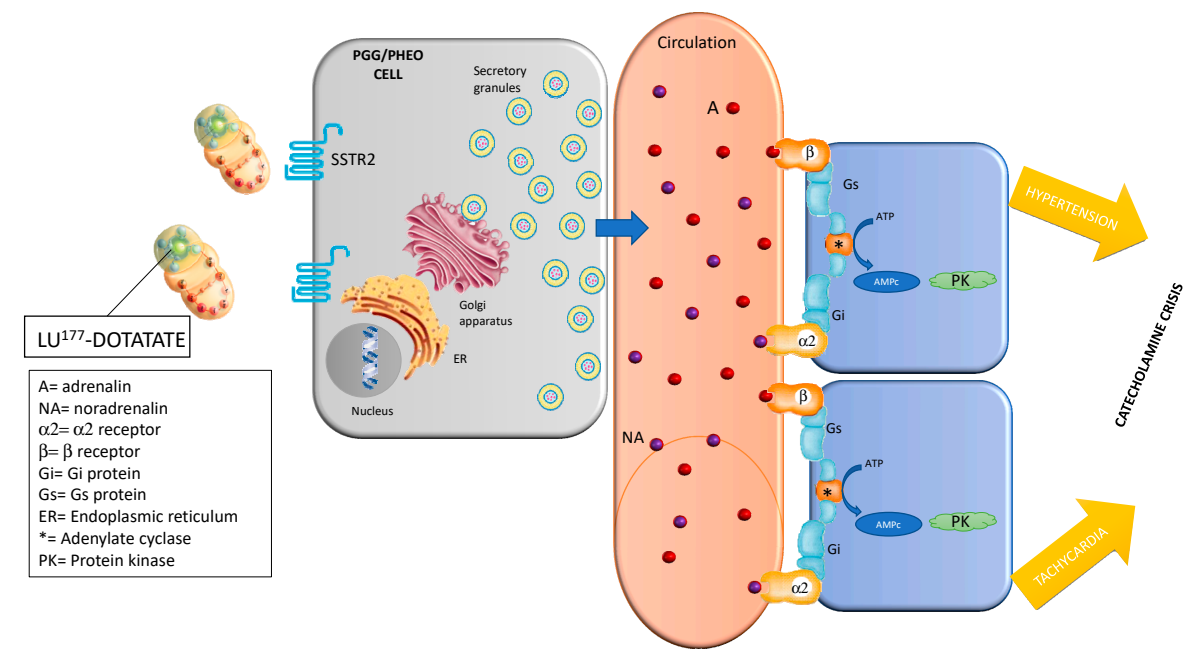

Figure 1. Physiopathology of hormonal crisis during Lu-DOTATATE treatment (catecholamine crisis). Somatostatin receptor 2 (SSTR2); adenosine triphosphate (ATP); cyclic adenosine monophosphate (AMPc); Paraganglioma (PGG); Pheochromocytoma (PHEO).

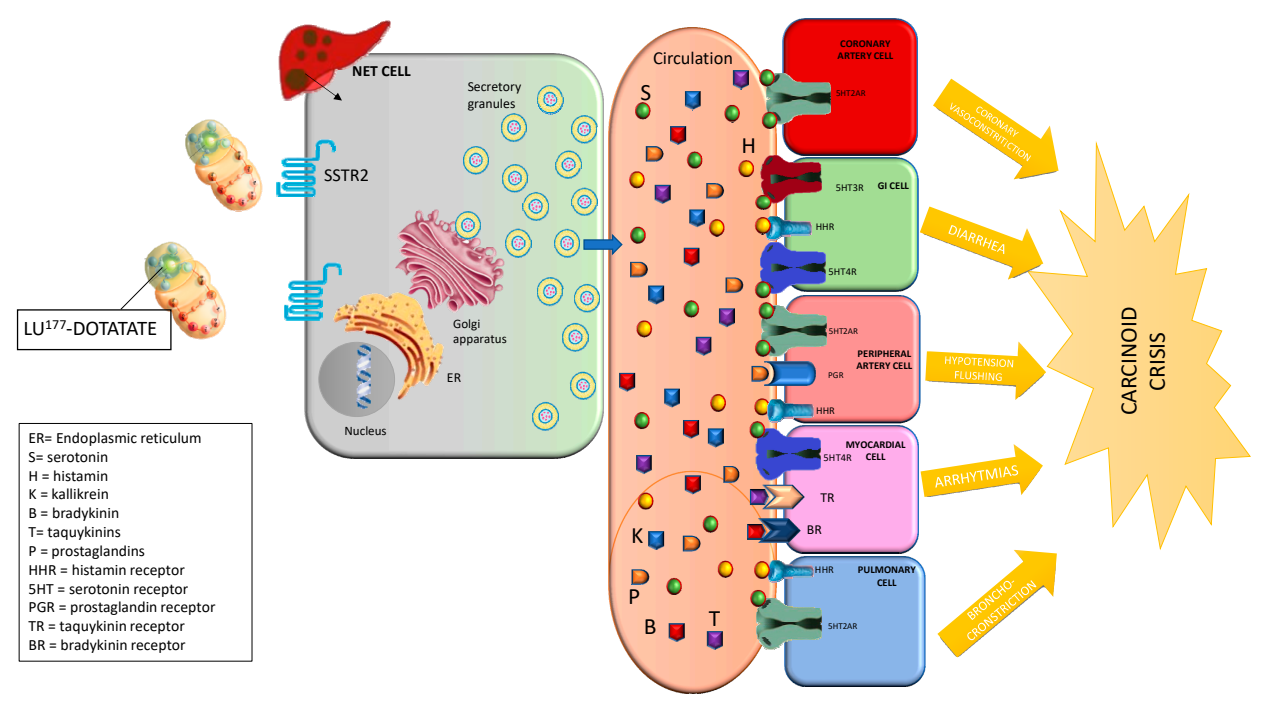

Figure 2. Physiopathology of hormonal crisis during Lu-DOTATATE treatment (carcinoid crisis).

The aim of this systematic review is to evaluate hormonal crisis during theragnosis with Lu-DOTA-TATE in functioning neuroendocrine tumors and to establish a practical guidance for the management and prevention of the most common hormonal crisis during radionuclide treatment with Lu-DOTA-TATE: carcinoid syndrome (CS) and catecholamine hypersecretion.

\section{Methods}

This systematic review was developed according to the Preferred Reporting Items for Systematic Reviews and Meta-Analyses (PRISMA) statement [18] (Figure 3) and conducted using MEDLINE (accessed from PubMed), Google Scholar and ClinicalTrials.gov. The search strategy was based on the Population, Intervention, Comparator, Outcome (PICO) framework [19] and was designed to find studies and reviews including a combination of Medical Subject Headings (MeSH) and non-MeSH keywords related to hormonal crisis during theragnosis with Lu-DOTA-TATE in functioning neuroendocrine tumors: "Peptide Receptor Radionuclide therapy" or "PRRT" and "hormonal crisis". 


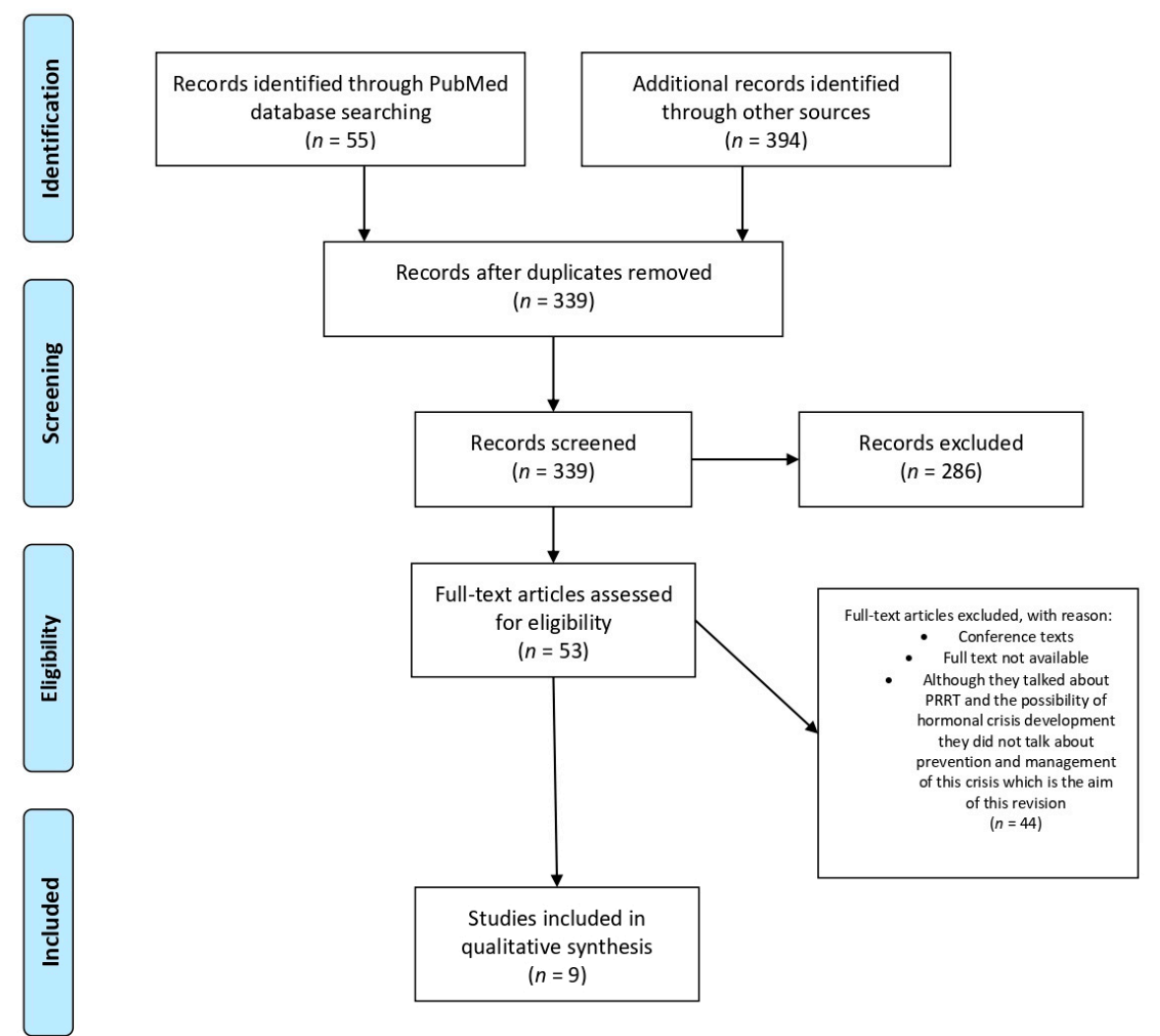

Figure 3. PRISMA flow diagram for studies retrieved through the searching and selection process.

As inclusion criteria, we considered that the study sample was human-based, full-text articles and articles available in English. On the other hand, as exclusion criteria, we excluded conference texts, full text not available, and text which, although they talked about PRRT and the possibility of hormonal crisis development, did not talk about prevention and management of this crisis which is the aim of this revision. Two teams consisted of three reviewers in each team (M.I.d.O.-G., J.-F.M.-T., M.A.M., M.L.-d.-1.-T., M.A., P.B.) with expertise in medical and health evaluations and training in research methodology. Any disagreements were resolved by a third researcher (J.M.S.).

According to the National Heart, Lung and Blood Institute [20], the validity of each included study was carried out using nine items to which either the affirmative (+), negative (-) or other, including "cannot determine", "not applicable" and "not reported", (that is unclear (?) answers) was allotted and classified in a rating of good (7-9), fair (4-6) or poor $(\leq 3)$ for each individual study.

\section{Results}

For this systematic review, the quality rating of manuscripts published, applying National Heart, Lung and Blood Institute criteria [20], is good. Literature searches located 449 citations potentially addressing all of the key questions of interest for the guideline evidence review. Overall, 53 studies were addressed and considered as evidence, and finally nine were relevant to this systematic review. Of these nine articles only one considered the management of all of the hormonal crisis; the rest either considered the prevention and/or management of carcinoid crisis, hormonal crisis in general excluding catecholaminergic crisis, catecholaminergic crisis or other hormonal complications. Two of the articles included PRRT with MIBG and/or Y90 treatment and management of hormonal crisis and were considered due to the physio-pathological similarity to $177 \mathrm{Lu}$. Table 2 summarizes the prevention and management approach considered in the different articles as well as the hormonal crisis described. 
Table 2. Articles selected in this systematic review.

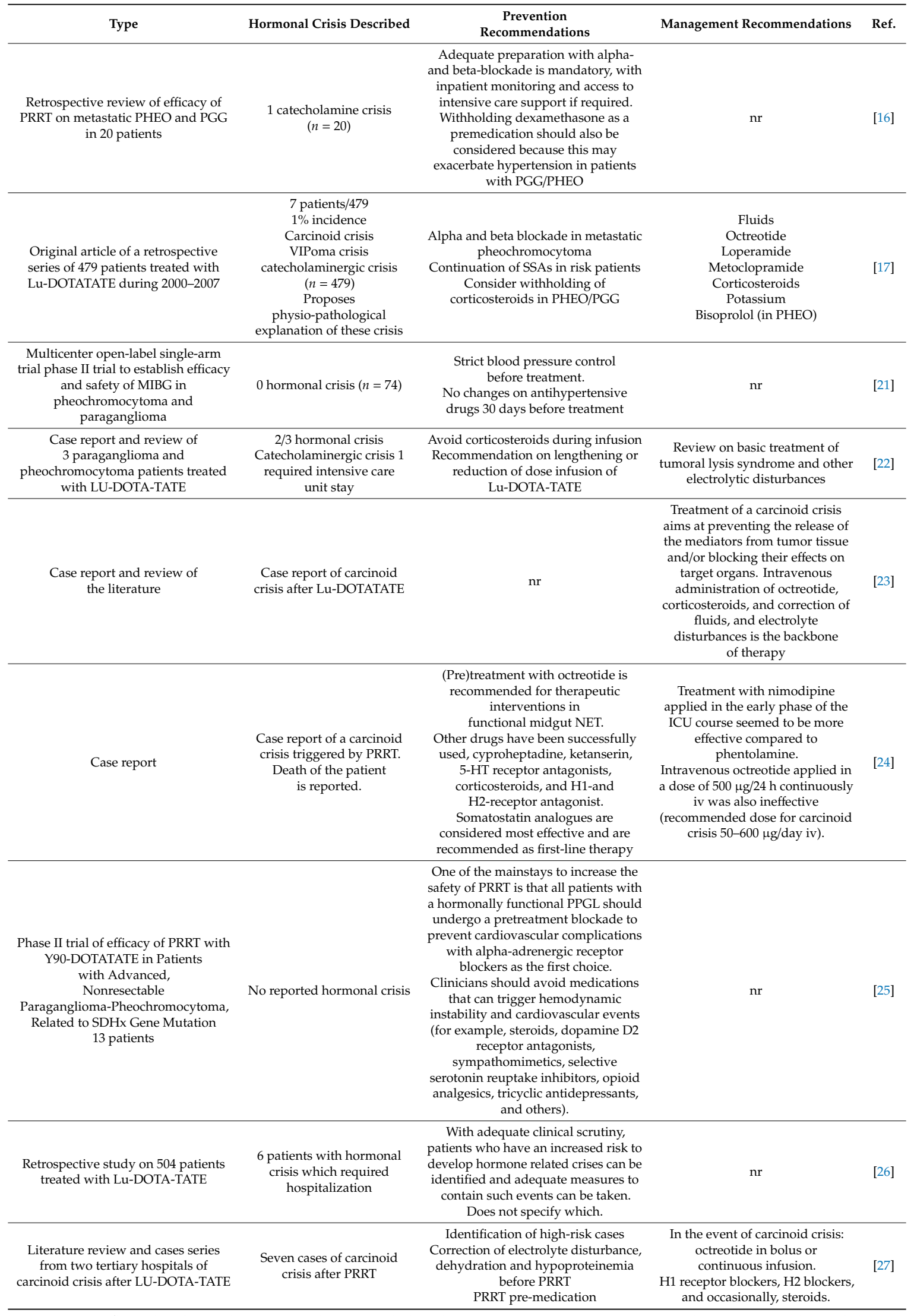

nr: not reflected in the study; paragangliomas and pheochromocytomas (PPG/PHEO); Peptide Receptor Radionuclide therapy (PRRT); metaiodobenzylguanidine (MIBG); Neuroendocrine tumor (NET); 5-hydroxytryptamine receptors (5-HT); histamine receptors (H1, H2); intensive care unit (ICU); vasoactive intestinal peptide (VIP). 


\section{Discussion}

After performing the systematic review, a description of the crisis reported in the literature and an approach proposal for the most frequent hormonal crisis described during PRRT with 177Lu-DOTATE will be described, i.e., carcinoid crisis and catecholaminergic crisis, as well as less frequent metabolic and hormonal complications.

\subsection{Carcinoid Crisis}

CS constitutes the clinical spectrum derived from the secretion of several bioactive amines from NETs and is the most frequent of the hormonal syndromes associated with NETs. CS usually appears in NETs originated in midgut (small intestine, appendix, right colon), and much more unfrequently in NETs originated in foregut (respiratory system, thymus, stomach, duodenum, pancreas). The reported incidence of CS is about $10 \%$ of patients with NETs [28]. Carcinoid crisis is a severe complication of CS, in which a massive release of biologically active substances takes place. It is a life-threatening episode manifested by a severe combination of CS symptoms, associated with hemodynamic instability and frequently tachycardia, arrhythmias, metabolic acidosis, and/or mental status disorders, along with a high mortality rate. Carcinoid heart disease is frequent in cases of CS and may add severity in the course of a carcinoid crisis [29]. The criteria for its definition are not well established, so its real incidence is unknown. The most relevant triggers are invasive procedures (e.g., surgery, invasive diagnostic or therapeutic techniques, and/or some medical treatments), including PRRT. According to the literature, incidence during PRRT would be between 1-10\% [17,26-33]. This usually takes place during the first Lu-DOTA-TATE cycle, either during the infusion or 12-48 $\mathrm{h}$ post-administration [27,29]. Authors agree on the importance of detecting individuals at high risk of developing carcinoid crisis before PRRT. Risk factors are previous CS, elevated 5-hydroxy-indolacetic acid (5-HIAA) and/or Chromogranin A, high tumor burden, metastatic disease (mainly hepatic), carcinoid heart disease, advanced patient age, and the use of drugs that cause histamine release such as sympathomimetic and $\beta 2$ agonist bronchodilators [26-29,31,32]. 5HIAA (5-hydroxy-indolacetic acid) determination in urine, a metabolite of 5-HT, constitutes the most useful biomarker in CS cases, or in patients in which prevention of a hormonal crisis might be of paramount importance in metastatic NETs which are going to undergo interventions that might predispose to a severe crisis, such as in PRRT [27]. Its determination requires excluding foods or drugs that interfere. A special diet which excludes certain foods (banana, pineapple, tomato, plums, kiwi, eggplant, avocado) must be initiated 3-5 days prior to its collection.

\subsubsection{Prevention}

In order to prevent carcinoid crisis, it is advisable to control CS as much as possible by optimizing medical treatment and the patient's nutritional status, and reducing tumor burden by debulking with surgical resection, radiofrequency ablation, selective internal radiotherapy, or embolization if possible. Nutritional status should be routinely assessed. and malnutrition should be corrected (nicotinamine, niacin, B12, pancreatic enzymes, fat-soluble vitamins supplementation, etc.). Correcting dehydration, electrolyte disorders, and hypoproteinemia are especially important, as well as avoiding alcohol, spicy food, and tryptophan rich food. Physical exertion may also exacerbate the symptoms of CS, so it should be avoided in the days prior to the administration of Lu-DOTA-TATE [24,27,31,32,34]. In functional NETs, and specifically if they present CS, the first-line pharmacological treatment are SSAs. The most frequently used are the i.m. octreotide long-acting release (LAR), at a dose of 10-30 mg every 28 days, or s.c. lanreotide autogel, at a dose of 60-120 mg every 28 days. SSA doses must be adapted to the patients' symptomatology, which may worsen with disease progression or tachyphylaxis. The short-acting analogue s.c. octreotide may be administered at a dose of 50-200 mcg once to three times a day. Initially it can be used as a test for the tolerability, or later on as a rescue injection when the patient is exhibiting uncontrolled symptomatology. In resistant patients a dose escalation may be needed 
by shortening the injection interval or increasing dosage, or switching to the other SSA alternative may be considered [34-37]. To avoid interference with Lu-DOTA-TATE administration in PRRT, SSA long-acting release should not be administered in the previous 28 days and short-acting analog s.c. octreotide in the previous $48 \mathrm{~h}$. However, in patients at high risk of carcinoid crisis, octreotide $100 \mathrm{mcg}$ could be administered before infusion and posteriorly a dose of $50 \mathrm{mcg} / \mathrm{h} / \mathrm{iv}$ could be maintained [27].

If the patient suffers from a severe CS, other medications may be used to control symptomatology. Diarrhea should be improved with standard diet and antidiarrheal advice, adapting the dose to the symptoms (Loperamide $4 \mathrm{mg}$ initially, with maximum doses $16 \mathrm{mg} /$ day, Codeine $10 \mathrm{mg}$, with maximum doses $30 \mathrm{mg} / 6 \mathrm{~h}$ ) [38]. Cyproheptadine, a serotonin receptor blocker, can be used in doses of $4 \mathrm{mg} / 8 \mathrm{~h}$. Telotristat ethyl has been found to reduce serotonin production by inhibiting tryptophan hydroxylase (TPH). It is indicated in combination with SSA therapy in adults with CS diarrhea inadequately controlled by SSA therapy $[17,24,29,32]$. Premedication with benzodiazepines and antihistamines can be useful to reduce anxiety before treatment with PRRT, but its administration is controversial, since histamine release may occur, especially with gastric or bronchial carcinoids [29]. Although steroids may not prevent anaphylactic shock, they can reduce episodes caused by nonspecific histamine release.

\subsubsection{Management and Treatment}

If CS symptoms appear during the Lu177-DOTATE infusion, the aim at that moment is to block hormonal secretion and the effect of the released mediators in order to control symptomatology (Table 3).

\subsection{Catecholaminergic Crisis}

A high percentage of patients with metastatic paraganglioma and pheochromocytoma express somatostatin receptors, especially SSTR2, which can be used for PRRT. Hormonal crises have been described due to catecholamine secretion in patients with metastatic paraganglioma or pheochromocytoma which can lead to severe hypertension, hypotension, pulmonary edema, myocardial ischemia and shock. These episodes of sudden release of hormones can be induced by multiple factors included physical activity, abdominal pressure, postural changes, anxiety, or smoking. Certain drinks or foods with a high concentration of tyramine (wine, cheese, beers) or drugs (tricyclic antidepressants, histamine, phenothiazine, glucocorticoids, high osmolality ionic contrast agents) and surgical procedures with or without anesthesia can also lead to this release [4].

Several cases have been reported of 131-MIBG treatment in which patients developed hypertension crisis during infusion and even myocardial infarction several days after treatment [39]. However, 177-LUDOTA-TATE treatment-induced catecholamine crises have been barely described. One of the cases described was of a malignant pheochromocytoma in which the patient developed hypotension, sweating and cardiac ischemia $24 \mathrm{~h}$ after infusion [17]. In this case, the patient was pretreated with glucocorticoids which may induce catecholamine crisis, as recently described in the literature [40]. Other centers have reported, $24 \mathrm{~h}$ following 177-LUDOTATE infusion, severe tumoral lysis syndrome which led to severe hypertension, shortness of breath, tachycardia, hyperkalemia, hyperphosphatemia and hypocalcemia with necessary admission to ICU [22]. Other patients developed severe hypotension or severe tachycardia during treatment infusion $[16,17,21,22,25,26,41]$.

The scientific community appears to be sensitized to the fact that pharmacological treatment of pheochromocytoma and functional paraganglioma before surgery is of vital importance in these patients. However, several authors agree that metastatic functional paraganglioma and pheochromocytoma, which are candidates for PRRT, need to be pretreated and certain protocols should be assessed during treatment infusion in order to avoid the hormonal crisis previously described $[16,17,21,25,41,42]$. 
Table 3. General measures for prevention and management of carcinoid crisis.

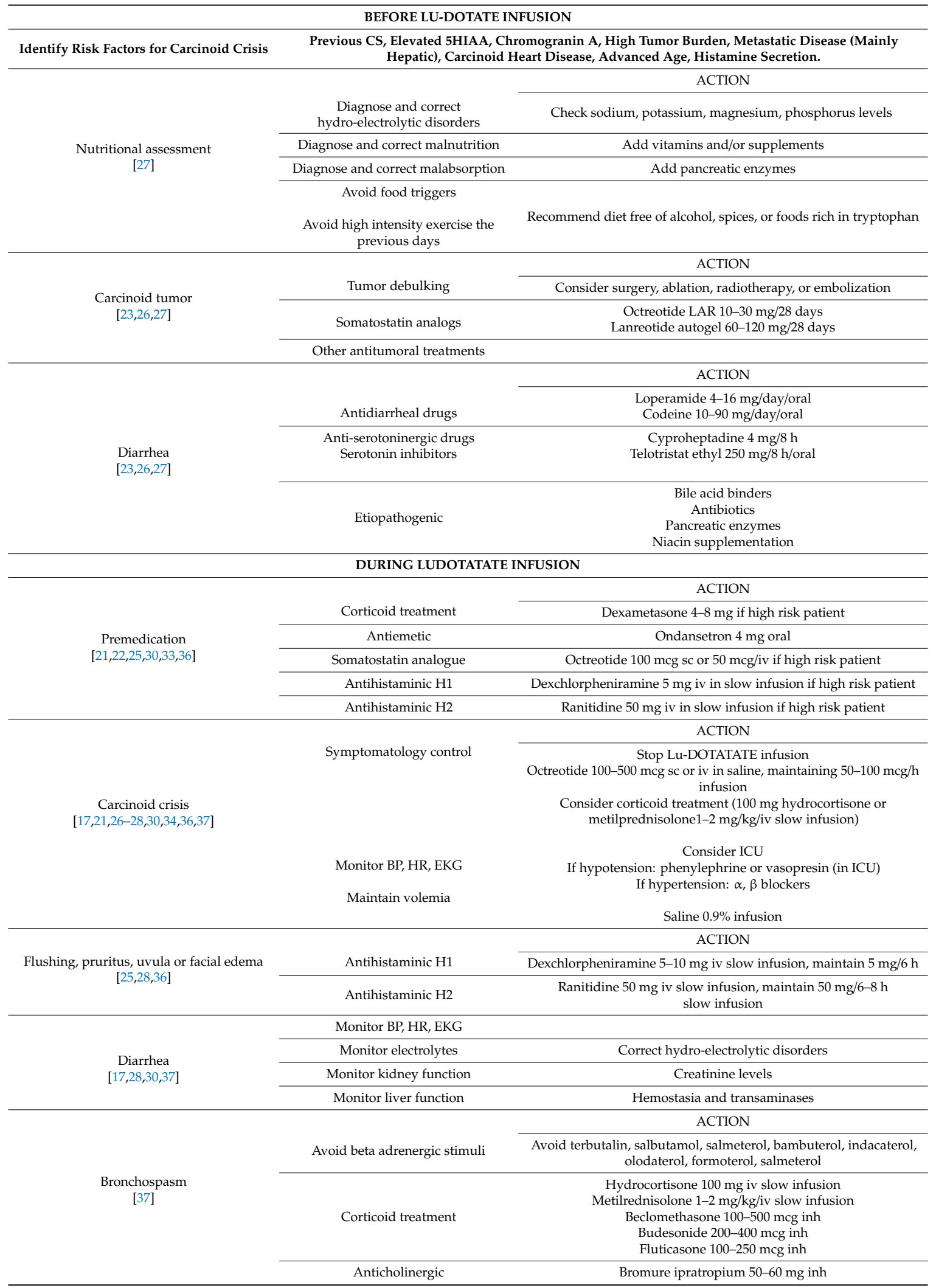

5-hydroxy-indolacetic acid (5-HIAA); carcinoid syndrome (CS); intensive care unit (ICU); blood pressure (BP); heart rate (HR); electrocardiogram (EKG). 


\subsubsection{Prevention}

In order to control hypertension or hemodynamic stability during radioisotope treatment, patients should undergo pharmacological treatment during the previous days. The aim of this treatment is to block the effects of released catecholamines during infusion. This preoperative therapy is aimed at normalization of blood pressure, heart rate and functioning of other organs; restoration of volume depletion; and prevention of PRRT induced catecholamine storm and its consequences on the cardiovascular system. Nevertheless, international differences in available or approved therapies and a scarcity of evidence-based studies comparing different therapies has led to a lack of consensus [42-47].

Currently there are different medical approaches for patients with catecholamine-producing neoplasms [42,43]. The accepted regimens are combined alpha and beta-adrenergic blockade, calcium channel blockers and metyrosine (tyrosine hydroxylase inhibition) (Figure 4).
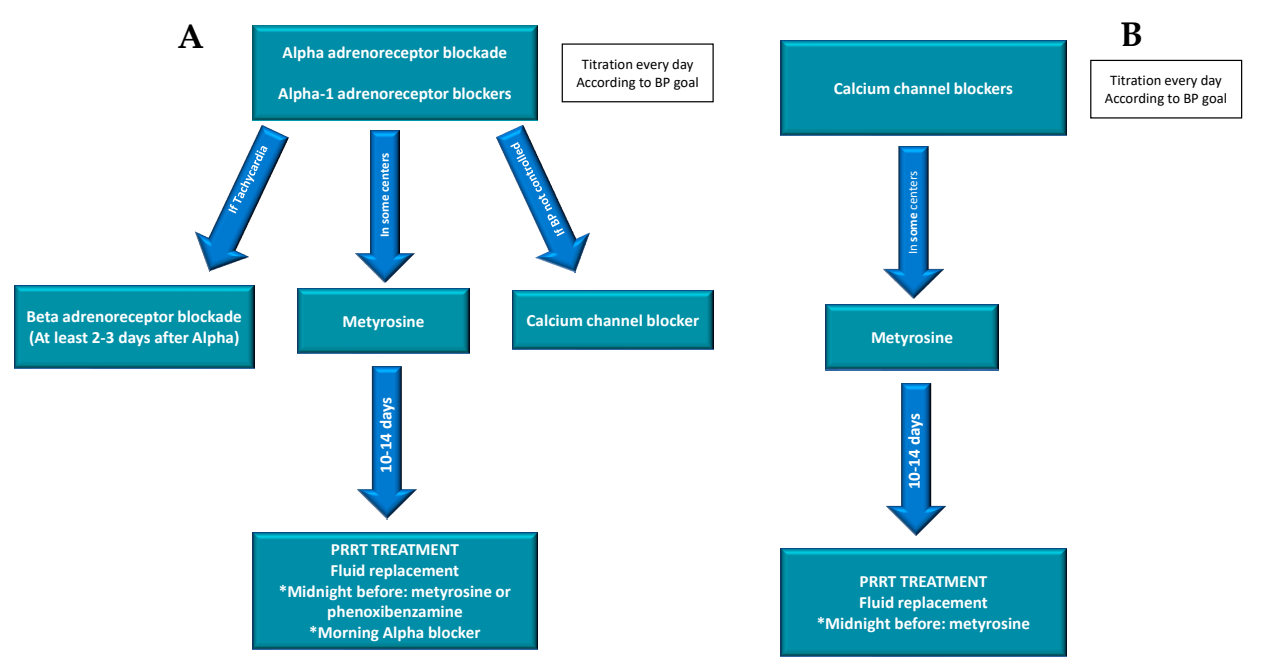

Figure 4. Accepted regimens for preparation of catecholamine producing tumors. (A): regimen performed with alpha blockade; (B): regimen performed with calcium channel blockers. ${ }^{*}$ specific management for the previous day and day of PRRT: Blood pressure (BP).

In our centers we preferably use the combined alpha and beta-adrenergic blockade. Alpha adrenergic blockade is administrated 10-14 days before treatment to normalize blood pressure and heart rate and expand the contracted blood volume due to the catecholamine secretion. If the patient has organ damage due to long-standing catecholamine excess, this period of alpha-blockade should be longer. Beta-blockers should never be used before the initiation of alpha-blockade in patients with functioning tumors as the unopposed alpha adrenergic effect can cause severe vasoconstriction which can lead to acute cardiac insufficiency, hypertensive crisis, and pulmonary edema. Added therapy with beta-receptor antagonists is required to counteract tachycardia induced by alpha-blocking agents. This tachycardia is a desired side-effect indicating that complete alpha blockade has been achieved. At this point, beta blockers can be added to reduce tachycardia. They must be added to alpha blockade not earlier than $2-3$ days later.

With the patient adequately prepared in the days before radioisotope treatment, several precautions should be considered during radioisotope infusion.

Frequently, patients during treatment with 177 LU-DOTA-TATE are pretreated with glucocorticoids infusion; however, this pre-treatment is concerning as catecholamine crisis induced by exogenous glucocorticoids has been described recently. Thus, pre-treatment with glucocorticoids should be avoided $[16,17,22,41]$.

On the other hand, there are several protocols of how to perform radioisotope infusion, and it seems that 177-LUDOTA-TATE infusion should be administered over $2 \mathrm{~h}$ at least and preferably over 
$4 \mathrm{~h}$ and not in 15-30 min as described in the literature. During infusion the patient should be monitored closely and intensive care support should be available if needed [22,41].

\subsubsection{Management and Treatment}

Medical stabilization for pheochromocytoma/paraganglioma crisis requires an individualized approach depending on clinical presentation. The severity of presentation can vary with regard to both hemodynamic stability and extent of organ dysfunction. There is therefore a clinical spectrum, but currently no accepted classification system for this hormonal crisis. In order to control this, general measures and specific treatments can be applied (Table 4) [17,22,43-47].

Table 4. General measures for prevention and management of catecholamine crisis.

\begin{tabular}{|c|c|c|}
\hline \multicolumn{3}{|c|}{ BEFORE LU-DOTATE INFUSION } \\
\hline $\begin{array}{l}\text { Identify Risk Factors } \\
\text { for Catecholamine } \\
\text { Crisis }\end{array}$ & \multicolumn{2}{|c|}{ Tumors larger than 3-4 cm, uncontrolled blood pressure, high catecholamine levels, or pretreatment orthostatic hypotension } \\
\hline $\begin{array}{l}\text { Nutritional assessment } \\
\qquad[27,42]\end{array}$ & $\begin{array}{l}\text { Diagnose and correct hydro-electrolytic disorders } \\
\text { Diagnose and correct malnutrition } \\
\text { Diagnose and correct constipation } \\
\text { Avoid high intensity exercise the previous days }\end{array}$ & $\begin{array}{c}\text { Check sodium, potassium, magnesium, phosphorus levels } \\
\text { Add vitamins and/or supplements } \\
\text { Specific diet for constipation }\end{array}$ \\
\hline \multirow{8}{*}{$\begin{array}{c}\text { Catecholamine } \\
\text { producing tumor } \\
{[32,45]}\end{array}$} & Tumor debulking & Consider surgery, ablation, radiotherapy, or embolization \\
\hline & \multirow{3}{*}{ Alpha adrenergic blockade } & $\begin{array}{l}\text { Initial dose: } 10 \mathrm{mg} 1-2 \text { times day } \\
\text { Titration: } 10-20 \mathrm{mg} \text { every } 2-3 \text { days } \\
\text { Average daily dose: } 20-100 \mathrm{mg} / \text { day } \\
\quad \text { Maximum dose: } 240 \mathrm{mg} / \text { day }\end{array}$ \\
\hline & & $\begin{array}{l}\text { Initial dose: } 0.5-1 \mathrm{mg} \text { per dose every } 4-6 \mathrm{~h} \\
\text { Average daily dose: } 2-5 \mathrm{mg} \text { two or three times a day } \\
\text { Maximum dose: } 20-24 \mathrm{mg} / \text { day }\end{array}$ \\
\hline & & $\begin{array}{l}\text { Initial dose: } 1 \mathrm{mg} / \text { day } \\
\text { Titration } \\
\text { Average dose: } 2-5 \mathrm{mg} / \text { day } \\
\text { Maximum dose: } 20 \mathrm{mg} / \text { day }\end{array}$ \\
\hline & \multirow{3}{*}{ Beta adrenergic blockade } & $25-50 \mathrm{mg}$ three to four times a day \\
\hline & & $12.5-25 \mathrm{mg}$ two to three times a day \\
\hline & & $20-80 \mathrm{mg}$ one to three times a day \\
\hline & Metyrosine & $\begin{array}{c}\text { Initial dose: } 250 \mathrm{mg} \text { orally every } 8-12 \mathrm{~h} \text { Titration } \\
\text { Average dose: } 1.5-2 \text { gr per day } \\
\text { High fluid intake to avoid crystalluria is suggested for patients taking more } \\
\text { than } 2 \mathrm{gr} / \text { day }\end{array}$ \\
\hline \multirow{8}{*}{$\begin{array}{l}\text { Catecholamine crisis } \\
\quad[24,29,45-49]\end{array}$} & Symptomatology control & $\begin{array}{l}\text { Stop Lu-DOTATATE infusion } \\
\text { Consider slowing infusion rate over } 2 \mathrm{~h} \text { at least and preferably during } 4 \mathrm{~h}\end{array}$ \\
\hline & Monitor BP, HR, EKG & \\
\hline & Maintain volemia & Saline $0.9 \%$ infusion \\
\hline & If hypertension & Captopril $50 \mathrm{mg}$ oral \\
\hline & If severe hypertension & $\begin{array}{l}\text { Sodium nitroprusside: } 0.5-5.0 \mathrm{mcg} / \mathrm{kg} / \mathrm{min} \text {, Maximum dose } 3 \mathrm{mcg} / \mathrm{kg} / \mathrm{min} \\
\text { Phentolamine: initial dose of } 1 \mathrm{mg} \text {, if necessary, repeat } 5 \mathrm{mg} \text { boluses or } \\
\text { continuous infusion } \\
\text { Nicardipine started at } 5 \mathrm{mg} / \mathrm{h} \text { and titrated for blood pressure control (may be } \\
\text { increased by } 2.5 \mathrm{mg} / \mathrm{h} \text { every } 15 \mathrm{~min} \text { up to a maximum of } 15 \mathrm{mg} / \mathrm{h} \text { ). }\end{array}$ \\
\hline & If hypertension + tachycardia & $\begin{array}{l}\text { Labetalol infusion } 20 \mathrm{mg} / \mathrm{iv} \text { in slow boluses every } 5-10 \mathrm{~min} \text { until a maximum } \\
\text { dose of } 300 \mathrm{mg} \text {. If continuous infusion is needed } 250 \mathrm{mg} \text { in } 250 \mathrm{~mL} \text { of glucose } \\
5 \% \text { at a rhythm of } 2-10 \mathrm{mg} / \mathrm{min} \text {. }\end{array}$ \\
\hline & If cardiac arrhythmias & $\begin{array}{l}\text { Lidocaine } 50-100 \mathrm{mg} \text { intravenously } \\
\text { Esmolol (50-200 } \mathrm{mcg} / \mathrm{kg} / \mathrm{min} \text { intravenously) }\end{array}$ \\
\hline & If other complications or not control & Always consider ICU \\
\hline
\end{tabular}

Blood pressure (BP); heart rate (HR); electrocardiogram (EKG); histamine receptors (H1, H2); intensive care unit (ICU). 


\subsection{Other Complications}

Other complications that may appear, although less severe than those previously described, but that must be taken into consideration in all patients are glycemic and electrolytic disorders [27,48]. Regarding glycemic disorders it is important to distinguish if the patient has a previous known diabetes or not (Table 5).

Table 5. Glycemic control and treatment in patients undergoing Peptide Receptor Radionuclide therapy (PRRT).

\begin{tabular}{|c|c|c|c|c|}
\hline $\begin{array}{c}\text { General } \\
\text { Recommendations }\end{array}$ & Before Infusion & Known Diabetes & Unknown Diabetes & After Infusion \\
\hline $\begin{array}{c}\text { Digital blood glucose } \\
\text { [49] }\end{array}$ & Glucose test & Every $\mathrm{h}$ & Every two h & $\begin{array}{c}\text { Before meals or every } \\
6 \mathrm{~h} \text { if fasting }\end{array}$ \\
\hline $\begin{array}{l}\text { Treated with oral drugs } \\
\text { [49] }\end{array}$ & $\begin{array}{l}\text { Do not administer oral DM } \\
\text { drugs that morning }\end{array}$ & \multirow{2}{*}{$\begin{array}{l}\text { Correction with rapid } \\
\text { insulin if indicated }\end{array}$} & \multirow{2}{*}{$\begin{array}{l}\text { Correction with rapid } \\
\text { insulin if indicated }\end{array}$} & \multirow{2}{*}{$\begin{array}{l}\text { Restart before dinner } \\
\text { if indicated }\end{array}$} \\
\hline & $\begin{array}{l}\text { If Metformin, withdrawal } \\
48 \mathrm{~h} \text { before. } \\
\text { DPP4 inhibitor, can be used }\end{array}$ & & & \\
\hline $\begin{array}{c}\text { Treated with insulin } \\
\text { [49] }\end{array}$ & Administer Basal dose & $\begin{array}{l}\text { Adjust with rapid } \\
\text { insulin every } 6 \mathrm{~h}\end{array}$ & & $\begin{array}{c}\text { Restart before lunch } \\
\text { if indicated }\end{array}$ \\
\hline $\begin{array}{l}\text { Fluid therapy } \\
\text { [49] }\end{array}$ & $\begin{array}{l}\text { Start glucose } 5 \% 500 \mathrm{~mL} / 6 \mathrm{~h} \\
\text { or } 10 \% 500 / 12 \mathrm{~h}\end{array}$ & & & $\begin{array}{l}\text { Stop glucose when } \\
\text { oral tolerance }\end{array}$ \\
\hline
\end{tabular}

If Diabetes Mellitus (DM) is present, record previous antidiabetic treatments and dose, time of last dose, self-glucose monitoring during the previous week, and fasting blood glucose on the day of administration to adjust the treatment on the day of infusion. Likewise, it is important to record medications with hyperglycemic potential, both in patients with DM as well as in those not known to be DM.

If hyperglycemia is present, glucose $\geq 180 \mathrm{mg} / \mathrm{dL}$, it will be treated according to the protocols of glycemic control during hospital stay. Generally, guidelines recommend adjustment with basal insulin, rapid insulin and additional corrections [49].

Hypoglycemia may appear not only in a DM patient but also if the patient has a metastatic insulinoma. Hypoglycemia will be defined according to the American Diabetes Association guidelines [50,51]: mild hypoglycemia (glycemia $56-70 \mathrm{mg} / \mathrm{dL}$ ), normally with mild symptoms, and severe hypoglycemia (glycemia less or equal that $55 \mathrm{mg} / \mathrm{dl}$ ), normally with neurological symptoms (Table 6). Management of hypoglycemia will always be intravenous and will differ according to its severity. If mild hypoglycemia, normally a glucose $10 \%$ infusion should be enough; if severe hypoglycemia a glucose $30-50 \%$ infusion may be needed and, in this case, it is recommended to stop the Lu-DOTA-TATE infusion and to restart it once it has been recovered.

Table 6. Hypoglycemia treatment in patients undergoing PRRT.

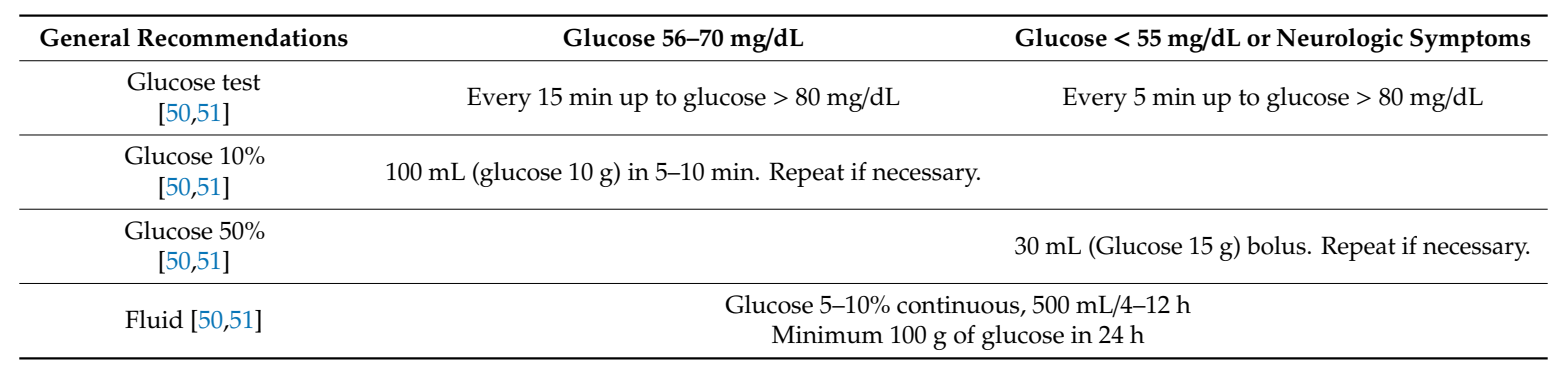


If the patient treated is a metastatic insulinoma and an uncontrolled hypoglycemia takes place, other medications may need to be added before hospital discharge. Usually pharmacological treatments to control hypoglycemia within metastatic insulinoma include diazoxide or SSAs cautiously.

Hypocalcemia is another dreaded complication. It is important to monitor hypocalcemia symptoms and to act accordingly if an episode of tetany takes place. Before Lu-DOTA-TATE, calcium level and corrected calcium level with albumin or total proteins must be assessed. If corrected calcium level is below $8 \mathrm{mg} / \mathrm{dL}$ or hypocalcemia symptoms are present, an intravenous treatment with calcium should be started. Usually, a calcium gluconate infusion in $50 \mathrm{~mL}$ of $5 \%$ dextrose or normal saline infused over 10 to $20 \mathrm{~min}$ is used (dosage equivalent to 90 or $180 \mathrm{mg}$ elemental calcium). This dose of calcium gluconate will raise the serum calcium concentration for only two or three hours. If hypocalcemia persists, a slow infusion of calcium containing $1 \mathrm{mg} / \mathrm{mL}$ of elemental calcium with normal saline or $5 \%$ dextrose water to provide a final volume of $500 \mathrm{~mL}$ should be added. Patients typically require $0.5-1.5 \mathrm{mg} / \mathrm{kg}$ of elemental calcium per h starting at an initial infusion rate of $50 \mathrm{~mL} / \mathrm{h}$ (equivalent to $50 \mathrm{mg}$ elemental/h). The dose should be adjusted to maintain the corrected calcium level concentration at the lower end of the normal range. For patients with hypoparathyroidism, calcitriol (oral dose of $0.25-0.5 \mathrm{mcg}$ twice daily) will be introduced and oral calcium ( $2-3 \mathrm{gr} / \mathrm{d}$ ) should be initiated as soon as possible. In some cases, it will be necessary to add oral or intravenous magnesium according to response, magnesium levels and kidney function.

Another infrequent complication is that related to tumoral lysis syndrome. This has been described after treatment, usually on the third day, in which uric acid, creatinine and urea increase, with a decreased glomerular filtration rate. Furthermore, hyperkalemia and an occasionally increase of phosphate and calcium levels may also be present. Tumoral lysis after treatment produces a deposit of uric acid and calcium phosphate crystals in the renal tubules with consequent deterioration of kidney function. It is an uncommon complication, but it is important to keep it in mind due to its appearance $2-4$ days after treatment [22,52]. Treatment prevention is essential, with adequate hydration and analysis that includes electrolytes, uric acid and kidney function. If it takes place, treatment will be symptomatic.

\section{Conclusions}

The favorable results obtained with PRRT for both NETs and paragangliomas foresee an increase in their indication and even a repositioning in earlier stages of the disease. Studies such as NETTER 2 [53], Study to Evaluate the Efficacy and Safety of Lutathera in Patients with G2 and G3 advanced pancreatic NETs, will answer these questions, among others. The possible adverse effects of PRRT treatments, and especially those of functioning NETs and paragangliomas, require adequate monitoring and treatment given their potential severity.

Functioning NETs and their possible complications should be treated in reference centers with an experienced multidisciplinary team in which each team member contributes with a specialized part of the care plan to optimize treatment with PRRT, as identification of high-risk individuals which are prone to developing hormonal crisis is essential

Further research is needed to establish the optimal 177Lu- DOTA-TATE protocols for treating NETs and paraganglioma in order to minimize severe adverse reactions. Treatment protocols could be modified by lengthening the infusion time of 177Lu-DOTA-TATE and/or lowering the initial treatment dose to help prevent adverse reactions or reduce their severity.

Author Contributions: M.I.d.O.-G., M.A.M., M.L.-d.-1.-T., M.A., P.B., J.M.S. and J.-F.M.-T. were responsible for the design, the systematic review and writing-review and editing. All authors have read and agreed to the published version of the manuscript.

Funding: This research received no external funding.

Conflicts of Interest: The authors declare no conflict of interest. 


\section{References}

1. Dasari, A.; Shen, C.; Halperin, D.; Zhao, B.; Zhou, S.; Xu, Y.; Shih, T.; Yao, J.C. Trends in the Incidence, Prevalence, and Survival Outcomes in Patients With Neuroendocrine Tumors in the United States. JAMA Oncol. 2017, 3, 1335-1342. [CrossRef] [PubMed]

2. WHO Classification of Tumours Editorial Board. Digestive system tumours. Lyon (France): International agency for research on cancer. In WHO Classification of Tumours Series, 5th ed.; WHO: Geneva, Switzerland, 2019; Volume 1.

3. Zandee, W.T.; Brabander, T.; Blazevic, A.; Kam, B.L.R.; Teunissen, J.J.M.; Feelders, R.A.; Hofland, J.; de Herder, W.W. Symtomatic and Radiological Response to 177Lu-DOTATATE for the Treatment of Functioning Pancreatic Neuroendocrine Tumors. J. Clin. Endocrinol. Metab. 2019, 104, 1336-1344. [CrossRef] [PubMed]

4. Hartmut, P.H.; Neumann, H.P.H.; Young, W.F.; Eng, C. Pheochromocytoma and Paraganglioma. N. Engl. J. Med. 2019, 381, 552-565. [CrossRef]

5. Jerzy, H.; Roman, T. Neuroendocrine neoplasms and somatostatin receptor subtypes expression. Nucl. Med. Rev. 2016, 19, 111-117. [CrossRef]

6. Remes, S.T.; Leijon, L.L.; Vesterinen, T.J.; Arola, J.J.; Haglund, C.H. Immunohistochemical Expression of Somatostatin Receptor Subtypes in a Panel of Neuroendocrine Neoplasias. J. Histochem. Cytochem. 2019, 1-19. [CrossRef] [PubMed]

7. Baumann, T.; Rottenburger, C.; Nicolas, G.; Wild, D. Gastroenteropancreatic neuroendocrine tumours (GEP-NET)- Imaging and staging. Best Pract. Res. Clin. Endocrinol. Metab. 2016, 30, 45-57. [CrossRef] [PubMed]

8. Ito, T.; Jensen, R.T. Molecular imaging in neuroendocrine tumors: Recent advances, controversies, unresolved issues, and roles in management. Curr. Opin. Endocrinol. Diabetes Obes. 2017, 24, 15-24. [CrossRef]

9. Lee, L.; Ito, T.; Jensen, R.T. Imaging of pancreatic neuroendocrine tumors: Recent advances, current status, and controversies. Expert Rev. Anticancer Ther. 2018, 18, 837-860. [CrossRef]

10. Haider, M.; Al-Toubah, T.; El-Haddad, G.; Strosberg, J. Molecular imaging and radionuclide therapy of neuroendocrine tumors. Curr. Opin. Endocrinol. Diabetes Obes. 2020, 27, 16-21. [CrossRef]

11. Hope, T.A.; Bergsland, E.K.; Bozkurt, M.F.; Graham, M.; Heaney, A.P.; Herrmann, K. Appropriate Use Criteria for Somatostatin Receptor PET Imaging in Neuroendocrine Tumors. J. Nucl. Med. 2018, 59, 66-74. [CrossRef]

12. Deppen, S.A.; Blume, J.; Bobbey, A.J.; Shah, C.; Graham, M.M.; Lee, P.; Delbeke, D.; Walker, R.C. 68Ga-DOTATATE Compared with 111In-DTPA-Octreotide and Conventional Imaging for Pulmonary and Gastroenteropancreatic Neuroendocrine Tumors: A Systematic Review and Meta-Analysis. J. Nucl. Med. 2016, 57, 872-878. [CrossRef] [PubMed]

13. Desai, H.; Borges-Neto, S.; Wong, T.Z. Molecular Imaging and Therapy for Neuroendocrine Tumors. Curr. Treat Opt. Oncol. 2019, 20, 78. [CrossRef] [PubMed]

14. Crona, J.; Taïeb, D.; Pacak, K. New Perspectives on Pheochromocytoma and Paraganglioma: Toward a Molecular Classification. Endocr. Rev. 2017, 38, 489-515. [CrossRef] [PubMed]

15. Brabander, T.; van der Zwan, W.A.; Teunissen, J.J.M.; Kam, B.L.R.; Feelders, R.A.; de Herder, W.W.; van Eijck, C.H.J.; Franssen, G.J.H.; Krenning, E.P.; Kwekkeboom, D.J. Long-Term Efficacy, Survival, and Safety of [177 Lu-DOTA 0,Tyr 3]octreotate in Patients With Gastroenteropancreatic and Bronchial Neuroendocrine Tumors. Clin. Cancer Res. 2017, 23, 4617-4624. [CrossRef]

16. Kong, G.; Grozinsky-Glasberg, S.; Hofman, M.S.; Callahan, J.; Meirovitz, A.; Maimon, O.; Pattison, D.A.; Gross, D.J.; Hicks, R.J. Efficacy of Peptide Receptor Radionuclide Therapy for Functional Metastatic Paraganglioma and Pheochromocytoma. J. Clin. Endocrinol. Metab. 2017, 102, 3278-3287. [CrossRef] [PubMed]

17. De Keizer, B.; van Aken, M.O.; Feelders, R.A.; de Herder, W.W.; Kam, B.L.; van Essen, M.; Krenning, E.P.; Kwekkeboom, D.J. Hormonal crisis following receptor radionuclide therapy with the radiolabeled somatostatin analogue [177Lu-DOTA0,Tyr3]octreotate. Eur. J. Nucl. Med. Mol. Imaging 2008, 35, 749-755. [CrossRef]

18. Moher, D.; Liberati, A.; Tetzlaff, J.; Altman, D.G.; Group, P. Preferred reporting items for systematic reviews and meta-analyses: The PRISMA statement. PLoS Med. 2009, 6, e1000097. [CrossRef] 
19. Liberati, A.; Altman, D.G.; Tetzlaff, J.; Mulrow, C.; Gøtzsche, P.C.; Ioannidis, J.P.; Clarke, M.; Devereaux, P.J.; Kleijnen, J.; Moher, D. The PRISMA statement for reporting systematic reviews and meta-analyses of studies that evaluate health care interventions: Explanation and elaboration. Ann. Intern. Med. 2009, 151, 65-94. [CrossRef]

20. National Heart, Lung and Blood Institute. Quality Assessment Tool for Case Series Studies. Available online: https://www.nhlbi.nih.gov/health-topics/study-quality-assessment-tools (accessed on 6 May 2020).

21. Pryma, D.A.; Chin, B.B.; Noto, R.B.; Dillon, J.S.; Perkins, S.; Solnes, L.; Kostakoglu, L.; Serafini, A.N.; Pampaloni, M.H.; Jensen, J.; et al. Efficacy and Safety of High-Specific-Activity 131I-MIBG Therapy in Patients with Advanced Pheochromocytoma or Paraganglioma. J. Nucl. Med. 2019, 60, 623-630. [CrossRef]

22. Makis, W.; McCann, K.; Mc Ewan, A. The Challenges of Treating Paraganglioma Patients With (177)-Lu-DOTATATE PRRT: Catecholamine Crisis, Tumor Lysis Syndrome and the Need of Modification of Treatment Protocols. Nucl. Med. Mol. Imaging 2015, 49, 223-230. [CrossRef]

23. Yadav, S.K.; Jha, C.K.; Patil, S.; Datta, D.; Mishra, A.; Pradhan, P.K. Lutetium therapy-induced carcinoid crisis: A case report and review of literature. J. Can. Res. Ther. 2020. [CrossRef]

24. Stentzel, J.; Noe, S.; Holzapfel, K.; Erlmeier, F.; Eyer, F. Fatal Systemic Vasoconstriction in a Case of Metastatic Small-Intestinal NET. Case Rep. Gastrointest. Med. 2017, 2017, 9810194. [CrossRef]

25. Kolasinska -C’wikła, A.; Peczkowska, M.; Cwikła, J.B.; Michałowska, I.; Pałucki, J.M.; Bodei, L.; Lewczuk-My'slicka, A.; Januszewicz, A. A Clinical Efficacy of PRRT in Patients with Advanced, Nonresectable, Paraganglioma-Pheochromocytoma, Related to SDHx Mutation. J. Clin. Med. 2019, 8, 952. [CrossRef]

26. Kwekkeboom, D.J.; de Herder, W.W.; Kam, B.L.; van Eijck, C.H.; van Essen, M.; Kooij, P.P.; Feelders, R.A.; van Aken, M.O.; Krenning, E.P. Treatment With the Radiolabeled Somatostatin Analog [177Lu-DOTA0,Tyr3]Octreotate: Toxicity, Efficacy, and Survival. J. Clin. Oncol. 2008, 26, 2124-2130. [CrossRef] [PubMed]

27. Tapia Rico, G.; Li, M.; Pavlakis, N.; Cehic, G.; Price, T.J. Prevention and management of carcinoid crises in patients with high-risk neuroendocrine tumours undergoing peptide receptor radionuclide therapy (PRRT): Literature review and case series from two Australian tertiary medical institutions. Cancer Treat. Rev. 2018, 66, 1-6. [CrossRef] [PubMed]

28. Aluri, V.; Dillon, J.S. Biochemical Testing in Neuroendocrine Tumors. Endocrinol. Metab. Clin. N. Am. 2017, 46, 669-677. [CrossRef]

29. Keskin, O.; Yalcin, S. Carcinoid Crisis in the Intensive Care Unit; Nates, J.L., Price, K.J., Eds.; Springer International Publishing: Cham, Switzerland, 2020; pp. 995-1001.

30. Raedler, L. Lutathera (Lutetium Lu 177 Dotatate) First Radioactive Drug Approved for Gastroenteropancreatic Neuroendocrine Tumors. Oncol. Guide FDA Approv. Spec. Feature 2019, 37-39.

31. Mittra, E. Neuroendocrine Tumor Therapy: 177Lu-DOTATATE. AJR 2018, 211, 278-285. [CrossRef]

32. Hope, T.; Abbott, A.; Colucci, K.; Bushnell, D.L.; Gardner, L.; Graham, W.S.; Lindsay, S.; MetzDC, P.D.; Stabin, M.G.; Strosberg, J.R. NANETS/SNMMI Procedure Standard for Somatostatin Receptor-Based Peptide Receptor Radionuclide Therapy with 177Lu-DOTATATE. J. Nucl. Med. 2019, 60, 937-943. [CrossRef]

33. Ito, T.; Lee, L.; Jensen, R. Carcinoid-syndrome: Recent advances, current status and controversies. Curr. Opin. Endocrinol. Diabetes Obes. 2018, 25, 22-35. [CrossRef]

34. Gut, P.; Waligórska-Stachura, J.; Czarnywojtek, A.; Sawicka-Gutaj, N.; Bączyk, M.; Ziemnicka, K.; Fischbach, J.; Wolinski, K.; Kaznowski, J.; Wrotkowska, E. Management of the hormonal syndrome of neuroendocrine tumors. Arch. Med. Sci. 2017, 3, 515-524. [CrossRef] [PubMed]

35. Hofland, J.; Zandee, W.T.; de Herder, W.W. Role of biomarker tests for diagnosis of neuroendocrine tumours. Nat. Rev. Endocrinol. 2018, 29, 656-669. [CrossRef] [PubMed]

36. Guo, L.-J.; Tang, C.-W. Somatostatin analogues do not prevent carcinoid crisis. Asian Pac. J. Cancer Prev. 2014, 15, 6679-6683. [CrossRef] [PubMed]

37. Hofland, J.; Herrera-Martinez, A.D.; Zandee, W.T.; de Herder, W.W. Management of carcinoid syndrome: A systematic review and meta-analysis. Endocr. Relat. Cancer 2019, 26, R145-R156. [CrossRef] [PubMed]

38. Naraev, B.G.; Halland, M.; Halperin, D.M.; Purvis, A.J.; O’Dorisio, T.M.; Halfdanarson, T.R. Management of Diarrhea in Patients With Carcinoid Syndrome. Pancreas 2019, 48, 961-972. [CrossRef] [PubMed]

39. Safford, S.D.; Coleman, R.E.; Gockerman, J.P.; Moore, J.; Feldman, J.M.; Leight, G.S., Jr.; Tyler, D.S.; Olson, J.A., Jr. Iodine-131 metaiodobenzylguanidine is an effective treatment for malignant pheochromocytoma and paraganglioma. Surgery 2003, 134, 956-962. [CrossRef] 
40. Rosas, A.L.; Kasperlik-Zaluska, A.A.; Papierska, L.; Bass, B.L.; Pacak, K.; Eisenhofer, G. Pheochromocytoma crisis induced by glucocorticoids: A report of four cases and review of the literature. Eur. J. Endocrinol. 2008, 158, 423-429. [CrossRef]

41. Mak, I.; Hayes, A.; Khoo, B.; Grossman, A. Peptide Receptor Radionuclide Therapy as a Novel Treatment for Metastatic and Invasive Phaeochromocytoma and Paraganglioma. Neuroendocrinology 2019, 109, 287-298. [CrossRef]

42. Martucci, V.; Pacak, K. Pheochromocytoma and Paraganglioma: Diagnosis, Genetics, Management, and Treatment. Curr. Probl. Cancer 2014, 38, 7-41. [CrossRef]

43. Del Olmo-García, M.I.; Palasí, R.; Camara, R.; Ponce, J.L.; Merino-Torres, J.F. Surgical and pharmacological management of functioning pheochromocytoma and paraganglioma. In On Paraganglioma: A Multidisciplinary Approach; Mariani-Costantini, R., Ed.; Codon Publications: Brisbane, Australia, 2019.

44. Ramachabdran, R.; Rewari, V. Current perioperative management of pheochromoytomas. Indian J. Urol. 2017, 33, 19-25. [CrossRef]

45. Fishbein, L.; Orlowski, R.; Cohen, D. Pheochromocytoma/paraganglioma: Review of perioperative management of blood pressure and update on genetic mutations associated with pheochromocytoma. J. Clin. Hypertens. 2013, 15, 428-434. [CrossRef] [PubMed]

46. Cohen, D.; Fishbein, L. Hypertension: A companion to Braunwald's Heart Disease Secondary Hypertension, 1st ed.; Elsevier: Chicago, IL, USA, 2018; pp. 136-143.

47. Pacak, K. Perioperative management of the pheochromocytoma patient. J. Clin. Endocrinol. Metab. 2007, 92, 4069-4079. [CrossRef] [PubMed]

48. Zaknun, J.; Bodei, L.; Mueller-Brand, J.; Pavel, M.; Baum, R.P.; Hörsch, D.; O’Dorisio, M.S.; O'Dorisiol, T.M.; Howe, J.R.; Cremonesi, M.; et al. The joint IAEA, EANM, and SNMMI practical guidance on peptide receptor radionuclide therapy (PRRNT) in neuroendocrine tumours. Eur. J. Nucl. Med. Mol. Imaging 2013, 40, 800-816. [CrossRef] [PubMed]

49. American Diabetes Association. Diabetes Care in the Hospital: Standards of Medical Care in Diabetes 2020. Diabetes Care 2020, 43, S193-S202. [CrossRef]

50. American Diabetes Association. Glycemic Targets: Standards of Medical Care in Diabetes 2020. Diabetes Care 2020, 43, S66-S76. [CrossRef]

51. International Hypoglycaemia Study Group. Minimizing Hypoglycemia in Diabetes. Diabetes Care 2015, 38, 1583-1591.

52. Huang, K.; Brenner, W.; Prasad, V. Tumor Lysis Syndrome: A Rare but Serious Complication of Radioligand Therapies. J. Nucl. Med. 2019, 60, 752-755. [CrossRef]

53. Study to Evaluate the Efficacy and Safety of Lutathera in Patients With Grade 2 and Grade 3 Advanced GEP-NET (NETTER-2). Available online: https://clinicaltrials.gov/ct2/show/NCT03972488 (accessed on 6 May 2020). 